\title{
ANALYSIS OF IMPACT OF METEOROLOGICAL CONDITIONS ON HUMAN FACTORS IN ESTIMATING THE RISK OF RAILWAY ACCIDENTS
}

\author{
Dejan ALEKSIĆ ${ }^{*}$, Milan MARKOVIĆ², Marko VASILJEVIĆ 3 , Gordan STOJIĆ 4 , \\ Norbert PAVLOVIC ${ }^{5}$, Ilija TANACKOV ${ }^{6}$ \\ ${ }^{1}$ Railway Technical School, Belgrade, Serbia \\ ${ }^{2,5}$ Faculty of Transport and Technical Engineering, University of Belgrade, Serbia \\ ${ }^{3}$ Faculty of Transport and Technical Engineering, University of East Sarajevo, Bosnia and Herzegovina \\ ${ }^{4,}{ }^{6}$ Faculty of Technical Science, University of Novi Sad, Serbia
}

Received 19 April 2016; revised 10 October 2016; accepted 8 November 2016; first published online 31 August 2017

\begin{abstract}
This paper explores the accidents that occurred in the railway system of Serbian Railways from 2006 to 2012. The total number of the sample observed includes 3983 accidents, of which 2725 or $68.41 \%$ were caused by the human factor. One of the major contemporary problems - global climate change and the increase of average temperatures has not yet been considered in the context of external factors for increasing the risk of accidents. The air pressure has become accepted as an external factor, in addition to the air temperature. It is assumed that temperature and air pressure have a significant impact on the risk of railway accidents occurrence (taking only accidents caused by a human factor into account). This assumption was made based on reduced cognitive abilities of railway staff as a result of extreme differences in temperature and air pressure. In this paper, the emphasis is put on Railway Crossings (RC) as sites where two forms of traffic intersect, since it is noticed that certain weather conditions have a significant effect on occurrence of accidents. The analysis of the observed sample of 266 accidents that occurred on RC shows that the risk of accident occurrence is significantly higher at low temperatures (from -10 to $0{ }^{\circ} \mathrm{C}$ ) and high air pressures $(p>1010$ mbar), the risk being 2.17, that is 2.41 times higher than in standard (average) weather conditions. Additionally, in the case of high temperatures (above $20^{\circ} \mathrm{C}$ ) and low air pressures $(p<1010 \mathrm{mbar}$ ) the risk rises to 2.07 in comparison to average weather conditions. The absolute risk of railway accident occurrence appears at temperatures below $-10^{\circ} \mathrm{C}$ and air pressures higher than $1010 \mathrm{mbar}$, as well as at high temperatures $\left(T>25^{\circ} \mathrm{C}\right)$ and air pressures lower than 1010 mbar.
\end{abstract}

Keywords: temperature, air pressure, transport, railway crossing, seasons, Bayes' theorem.

\section{Introduction}

One of the fundamental goals of every railway management is to increase the safety of railway traffic by reducing the number of railway accidents.

Former analyses point out the tendency of decrease in the number of railway accidents in the last couple of decades (Evans 2011; Silla, Kallberg 2012), considering the higher number of safety devices, as well as scientific and technical progress in general.

Due to the number of factors that affect the occurrence of railway accidents, it is very hard to predict their occurrences (Evans 2003). Therefore, various models have been introduced (Oh et al. 2006; Mirabadi, Sharifian 2010; Ouyang et al. 2010; Underwood, Waterson
2014), which may provide solid results in terms of predicting the number of railway accidents.

However, it is rather hard to create a good model for anticipating the number of railway accidents, which results in a number of suggestions for accident prevention appearing in literature, such as introduction of improved safety systems (Evans, Verlander 1996), education of schoolchildren (Lobb et al. 2003), training of pedestrians for using overpasses (Lobb et al. 2001), introduction of active signalling systems at Railway Crossings (RC) (Tey et al. 2011) and many others.

Much attention is also paid to human factor as one of the most common causes of accidents; it has been confirmed that $70 \%$ of accidents occur due to the attention deficit of train drivers (Edkins, Pollock 1997).

*Corresponding author. E-mail: aleksicdejan33@yahoo.com 
Several factors that influence the attention deficit of train drivers and proceeding at the stop signal have been considered, including time pressure (reaction time of train driver), interaction with commands and the limited distance of signal visibility. It has been concluded that these factors have a large impact on the attention deficit of train drivers (Naweed 2013).

Nevertheless, the role of human factor in accidents should not be limited to train drivers only, with respect to the large number of staff that participate in the railway traffic operation and control. Almost all accidents are connected to the organizational factor (Baysari et al. 2008 ), i.e. to the problems in the organizing process, management or even to the organisational climate. As much as $30 \%$ of accidents occur due to the bad 'attitude' of personnel, which is reflected by low work ethic, lack of pride, low motivation, performing tasks without following the procedures, etc. (Edkins, Pollock 1997).

Perception of approaching railway vehicles by road users at RC does also have a significant impact on occurrence of accidents, since road users cannot estimate the speed of an approaching vehicle well if it is of large dimensions, as in the case of trains (Clark et al. 2013).

Privatisation of numerous railways imposed the question of traffic safety, as regards the change of ownership structure. The issue is considered to be rather significant in the case of Serbian Railways, as the company is currently undergoing a major restructuring. Some researches show that privatisation does not lead to regression of traffic safety as in the case of the railway systems of Great Britain (Evans 2007) and Japan (Evans 2010).

Statistics show that $5 \%$ of suicide attempts in almost all European countries occur on rail tracks (Silla, Luoma 2012). Unfortunately, $90 \%$ of them are successful. Because of that, there have been a number of proposals for developing strategies aimed at reduction of the number of suicides, as in the case of Swedish Railways (Rådbo et al. 2008).

Prevention of accidents is based on a good analysis of causes, dealing with consequences and making the right decisions aimed at prevention of the same or similar accidents. The answers on the questionnaire completed by railway workers in Norway (Størseth, Tinmannsvik 2012) led to the proposition about what should be learned from the accident that had occurred, as well as about what should be changed in order to prevent another occurrence of such accident. However, a serious approach to this problem is reflected in the competence of investigation body for railway accidents. It resulted in suggestions for establishment of multimodal investigation body (Cedergren, Petersen 2011) that would provide numerous benefits, as it would involve participation of sectors with various competences.

This paper will also explore the impact of temperature and air pressure on working capacity as possible external factors. Such analyses have not been done so far, though there is a considerable number of articles that discuss the dependence of working capacities on temperature.
Previous analyses have shown that the temperature significantly affects the performance of drivers of road vehicles (Daanen et al. 2003), their performance being drastically reduced by $16 \%$ in extreme cold $\left(5^{\circ} \mathrm{C}\right.$ in the cabin) and by $13 \%$ in extreme heat $\left(35^{\circ} \mathrm{C}\right.$ in the cabin). The author has concluded that thermo neutral temperature of $20^{\circ} \mathrm{C}$ has a positive effect on driving, i.e. driver's performance.

The specific impact of temperature was also observed from the aspect of thermoregulation in organisms (Imbeault et al. 2013), as well as of the necessity to take certain measures in extreme temperatures (Schlader et al. 2010), so that a human body could perform the basic tasks in extreme conditions. Although thermoregulation is, to some degree, independent of temperature, it does affect the time span of task performance and the working capacities for performance of certain tasks (Schlader et al. 2011).

This kind of research has become a necessity because of global warming of the Earth, as well as because of the overall impact of temperature, i.e. its increase, to which a man can adapt (Deschenes 2014).

In addition to assessment of motor skills, thermoregulation, etc., many articles deal with the impact of temperature on the appearance of people's aggressive behavior. Any deviation from the average (moderate) temperatures systematically increases the risk of conflict (Hsiang et al. 2013). The rise of temperature or extreme precipitation increases the interpersonal (personal) conflicts by $4 \%$, while the conflicts among groups increase by $14 \%$.

Although a number of authors indicate the effect of temperature on the working capacity of people, others do not find a significant dependence. Determination of a neutral temperature that would give the best results (Liu et al. 2013) depends on both physical and psychological factors. Moreover, some tests carried out on a number of people at low, medium and high temperatures do not indicate any connection between temperature and working capacities (Schlader et al. 2011).

All the above leads to a conclusion that climate factors in railway traffic, which may have a significant impact on accident occurrence, have not yet been considered. Given the existing researches on the impact of temperature on human capacity to perform certain jobs, we can assume that the air pressure might have a significant impact on accident occurrence.

Regardless of what the observed and researched factor for accident occurrence is, the purpose of all abovementioned papers, including this one, is to increase the level of safety, i.e. to determine and analyse the factors in order to reduce the risk of accident occurrence.

\section{Climate of Serbia}

As this paper analyses the effect of temperature on the working capacity of the railway staff and Third Parties (TP), the authors have provided a brief description of the climate in the observed area, as well as of the method of collecting data related to atmospheric conditions. 
The climate of Serbia can be described as moderatecontinental with more or less distinguished local characteristics. Geographic points that characterise synoptic situations which are significant for the weather and climate of Serbia include the Alps, the Mediterranean Sea, the Gulf of Genoa, the Pannonian Basin, the Carpathian Mountains and the Rhodopes, as well as mountains, hills, low- and medium-high mountain area with valleys and plateaus. Prevailing meridional location of river valleys and plains in the north of the country allow deep penetration of polar air masses to the south.

The largest part of Serbia lies in a moderate climate zone. The southwestern part of the country is located on the border of the subtropical and continental climates.

Meteorological Observation System of Serbia (MOSS) is a part of the Global Observing System (GOS) and consists of meteorological observatories and stations where measurement and observation is performed. The following parameters are measured and observed: present weather, past weather wind direction, speed and intensity, the amount, type and height of cloud base, visibility, air temperature, air humidity, atmospheric pressure, pressure tendency and its characteristics, extreme temperatures, precipitation intensity, duration and quantity and 16 more parameters

All measurements are made in weather stations, 31 of them being the main synoptic stations that take measurements every hour. In addition to these synoptic stations belonging to the Republic Hydrometeorological Service of Serbia (RHSS), there are 5 other belonging to the flight control, but its meteorological data are also being sent to the RHSS. Synoptic stations in Kosovo have not been in operation since 1999. There are also one hundred climatological stations in Serbia, where the values are read only at a certain time of the day (07:00, 14:00, 21:00).

Figure 1 shows the position of the synoptic stations according to the distance from the railway. In observation of railway accidents, meteorological data of the nearest synoptic station are always used, depending on the place and time of railway accident occurrence.

\section{Input data}

According to the Regulations on Registration of Railway Accidents ${ }^{1}$, based on the Law on Railways ${ }^{2}$, the term railway accident implies any event in the railway traffic in which one or more persons are killed, seriously or slightly injured, in which either small or considerable material damage is made or in which either small or big disruption to railway traffic occurs, that is an event resulting in endangering railway traffic or operation with difficulties.

\footnotetext{
1 There is a series of Regulations that stipulate various limitations. In this case, the Regulations define issues regarding railway accidents (the term, registration procedure, archiving, etc.);

2 The highest legal act of the Republic of Serbia that defines all issues regarding railways.
}

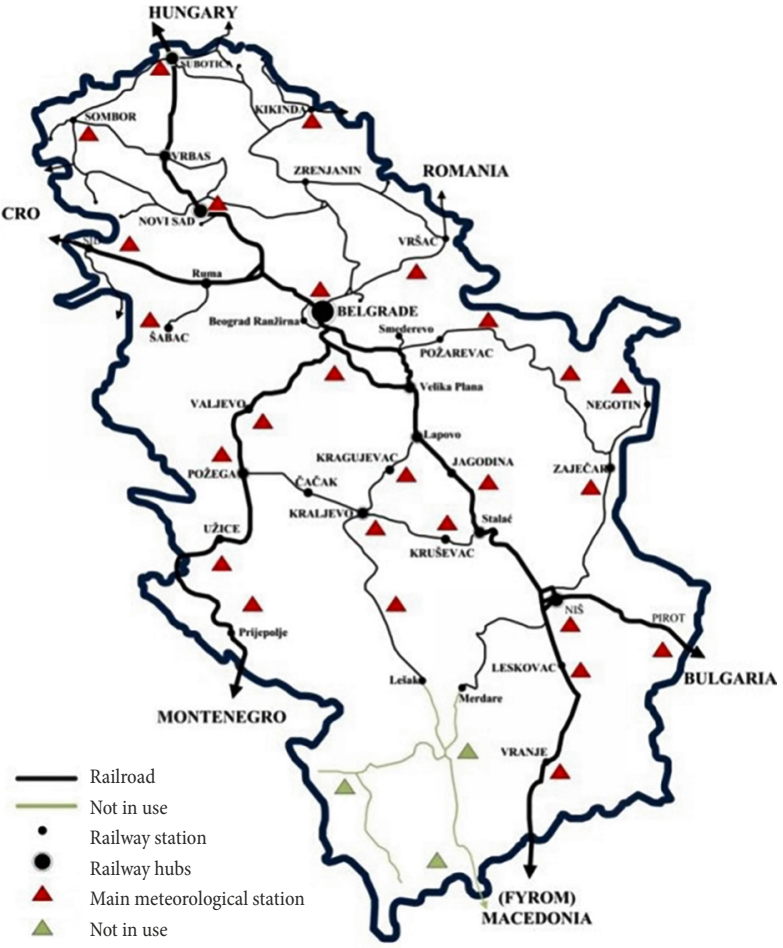

Figure 1. Positions of synoptic stations according to the distance from the railway

The analysis for the reference period of seven years, from 2006 to 2012, has shown that the total number of railway accidents was 3983, of which 2725 (68\%) was caused by a human factor. Figure 2 shows the structure of railway accidents on Serbian Railways (total of 3983 railway accidents), which includes, in addition to the human factor as the most common cause of railway accidents, technical failure (26\%) and force majeure (6\%).

Further study included only railway accidents caused by a human factor, a total of 2725, of which $29 \%$ occurred on RC and 39\% were caused by TP. Each of them was assigned the values of the air temperature and air pressure based on data obtained from the Republic Hydro meteorological Service of Serbia. Namely, every railway accident was observed individually. The nearest synoptic stations were found based on date, time and location of the railway accident (Figure 1) and values were assigned accordingly.

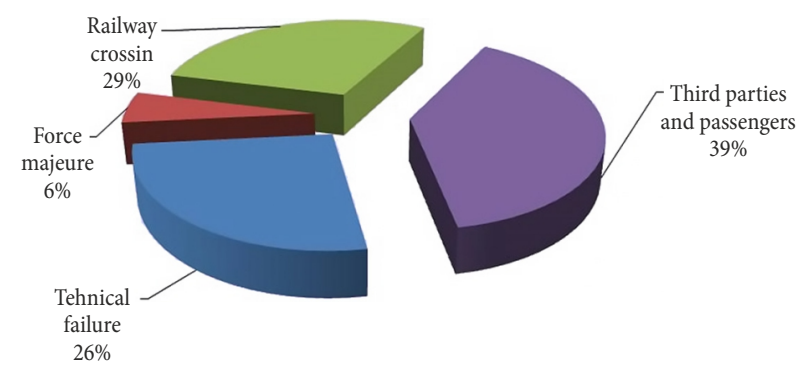

Figure 2. Structure of railway accidents on the Serbian Railways from 2006 to 2012 


\section{Analysis of the impact of air temperature and air pressure on the occurrence of railway accidents caused by human factor}

As stated in the previous section, the data used in the analysis referred only to the railway accident caused by a human factor, i.e. the total of 2725 accidents on the Serbian Railways in seven-year period. Although there is a detailed description of climatic conditions ${ }^{3}$ for every railway accident, based on the data of the RHSS, this paper emphasizes the air temperature and air pressure as external factors that may have a significant impact. This assumption has resulted from the large number of studies and articles about motor skills of people during extreme temperatures (Daanen et al. 2003; Schlader et al. 2011), when even the simplest tasks become demanding to a certain degree. This influence of temperature, combined with air pressure may have a significant impact on the occurrence of railway accidents.

However, the overview of all railway accidents caused by human factor does not show obvious effects of these external factors on the occurrence of railway accidents. On the other hand, the authors have noted some specific cases that occur at low temperatures $\left(T<0{ }^{\circ} \mathrm{C}\right)$ and simultaneously high pressures ( $p>1010 \mathrm{mbar}$ ), and provide high levels of risk for railway accident occurrence. Therefore, the data have been classified according to seasons, as low temperatures and high pressures at the same time indicate that the high risks of the railway accidents occurrence are likely to appear during autumn and winter.

The data have been divided and observed according to seasons as follows:

- for winter - December, January and February;

- for spring - March, April and May;

- for summer - June, July and August;

- for autumn - September, October and November.

The following figures show comparable histograms of distribution of recorded atmospheric pressures at the time of railway accidents involving TP and at RC in winter, spring, summer and autumn (Figure 3).

The ANalysis Of VAriance (ANOVA) ${ }^{4,5}$ confirmed the impact of seasonal factors on the value of atmospheric pressure at the time of railway accidents involving $\mathrm{TP}$ and at RC. The probability of variance compliance of the two sets of railway accidents is as follows:

\footnotetext{
${ }^{3}$ Collected data: air temperature, air pressure, dew point, pressure steam, relative humidity, pressure at sea level, changes in pressure for 3 hours, wind direction, wind speed, maximum wind speed, cloudiness, the low clouds, the mean clouds, the high clouds, visibility, precipitation, description of weather (past), etc.;

4 ANOVA tests the hypothesis that the means of two or more populations are equal. ANOVAs assess the importance of one or more factors by comparing the response variable means at the different factor levels. The null hypothesis states that all population means (factor level means) are equal while the alternative hypothesis states that at least one is different;

${ }^{5}$ Variance - is a measure of variability in statistics; the variance is equal to the square of the standard deviation.
}

- during winter the difference is significant, $p=0.012741<0.05^{6}$;

- during spring the difference is not significant, $p=0.628623>0.05$;

- during summer the difference is not significant, $p=0.142331>0.05$;

- during autumn, the difference is significant, $p=0.004634<0.05$.

Based on statistics about location (kilometric point), time, values of temperature and atmospheric pressure of railway accidents involving $\mathrm{TP}$ and at $\mathrm{RC}$, approximate graphs of functions have been formed. Time and temperature are chosen to be independent variables, while atmospheric pressure is dependent variable, as shown in the following figures: Figure 4 in winter, Figure 5 in spring, Figure 6 in summer, Figure 7 in autumn:

Distribution of air pressure depending on temperature and time of accident occurrence is given separately for accidents caused by TP and those that occur on RC.

High values of air pressure at low temperature can easily be noticed on Figures $4 \mathrm{~b}$ and $7 \mathrm{~b}$. On the other hand, equability of air pressure values is seen in Figures $5 \mathrm{a}, 5 \mathrm{~b}$ and $6 \mathrm{a}$. Figures $4 \mathrm{a}, 6 \mathrm{~b}, 7 \mathrm{a}$ and $7 \mathrm{~b}$ do not provide any clear visual information about the specific air pressures at the time of railway accident occurrence. Thus, it is difficult to estimate the critical values of air pressure at which the largest number of accidents would occur depending on temperature and time of the day (the time of railway accident occurrence).

Having taken the above-mentioned into account, the authors have applied the ANOVA and the data are shown in Table 1.

Further analysis confirmed the differences in variances of seasonal values of atmospheric pressures for the same types of railway accidents. The results of variance analysis are shown in Table 1.

The ANOVA has confirmed that there is no significant difference $(p=0.334794)$ between the values of atmospheric pressure at the time of railway accidents during the autumn and winter periods. Furthermore, there is no significant difference $(p=0.898516)$ in variances of atmospheric pressure at the time of railway accidents during spring and summer (Table 1).

However, factors of accidents at RC emphasize significant differences in distributions of atmospheric pressures during winter and spring $(p=0.000366)$, during winter and summer $(p=0.000021)$, during autumn and spring $(p=0.001806)$ and during autumn and summer $(p=0.000185)$. These results indicate a fair assumption of railway accidents occurrence depending on the season and the difference between warmer and colder periods.

It is a fact that the values of atmospheric pressure are subject to seasonal oscillations. The impact of seasonal factors on the value of atmospheric pressure at the time of railway accidents at RC is significantly different from the factors of railway accidents involving TP.

\footnotetext{
${ }^{6} p$ - calculated probability - the probability of finding the observed results when the null hypothesis $H_{0}$ of a study question is true or false. The null hypothesis is usually a hypothesis of 'no difference'. Most authors refer to statistically significant as $p<0.05$ and statistically highly significant as $p<0.001$ (less than one in a thousand chance of being wrong).
} 
a)

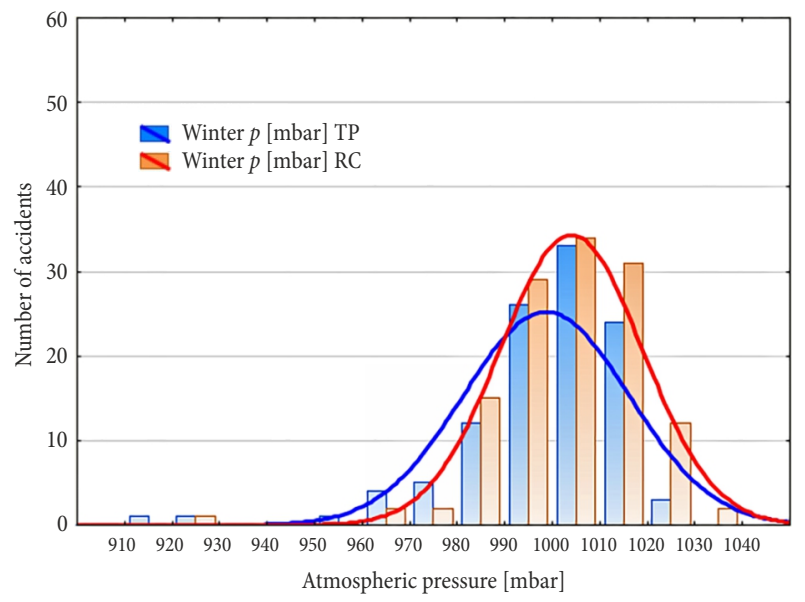

c)

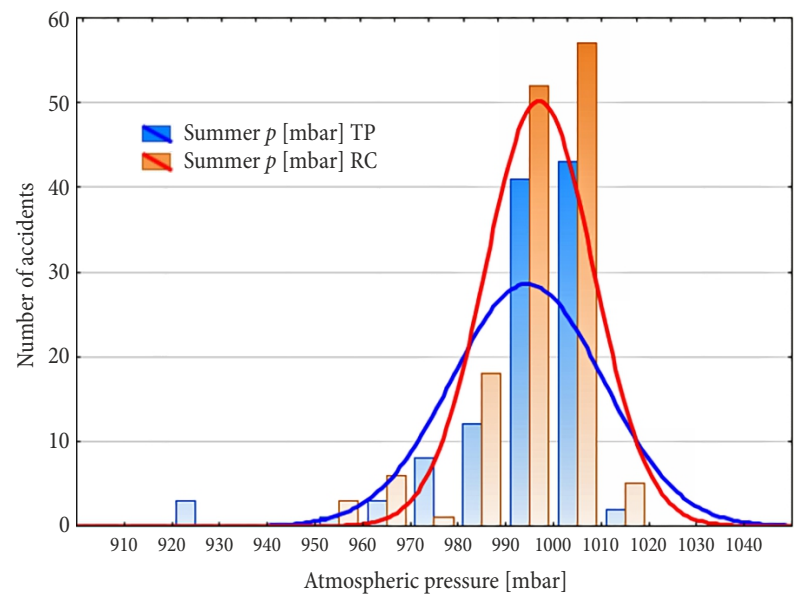

b)

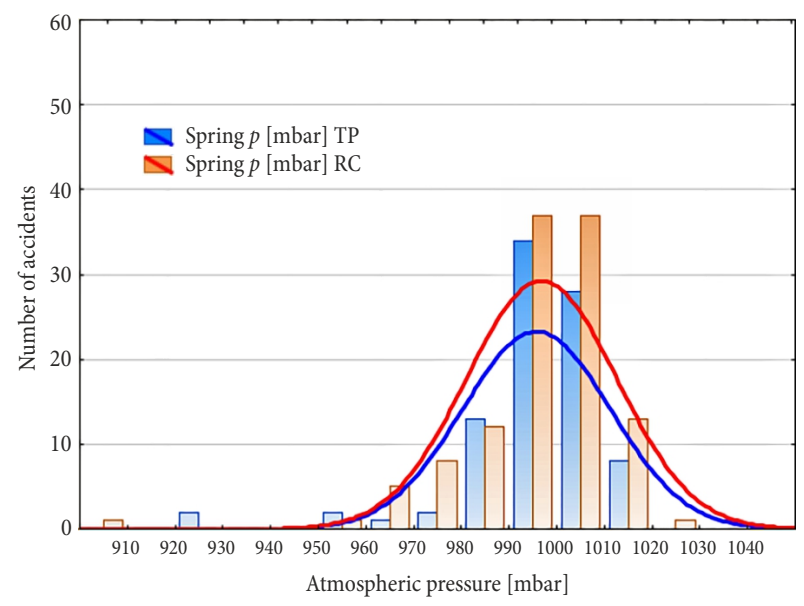

d)

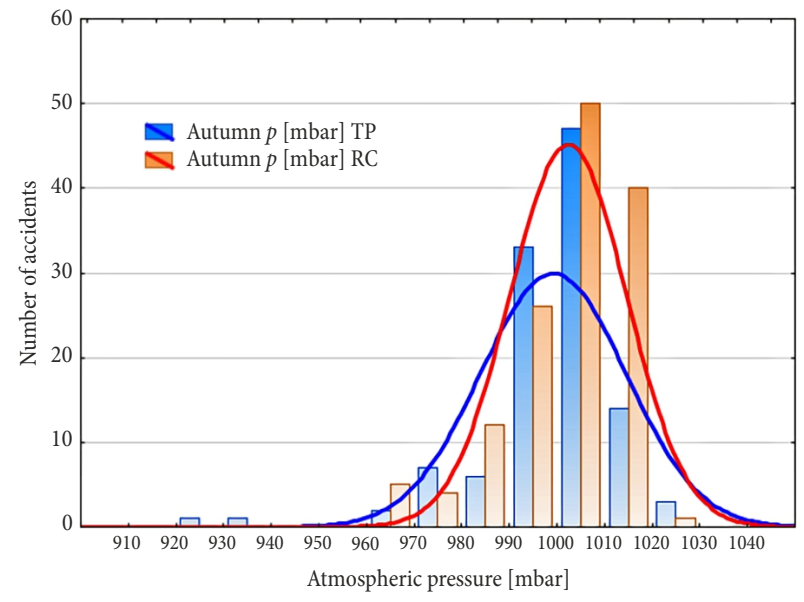

Figure 3. Histograms of distribution in: $a$ - winter; $b$ - spring; $c$ - summer; $d$ - autumn
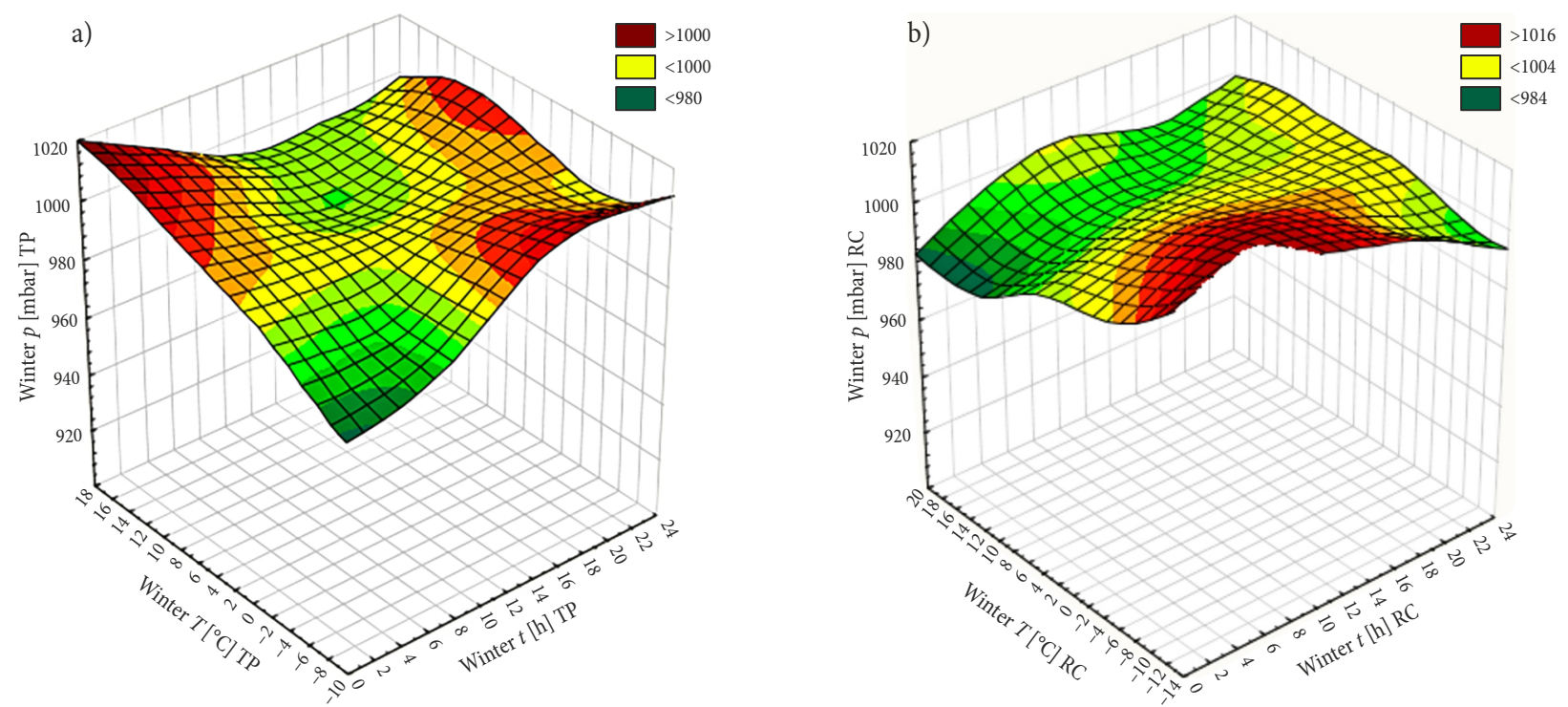

Figure 4. Distribution during winter: $\mathrm{a}$ - for TP; $\mathrm{b}$ - on RC 

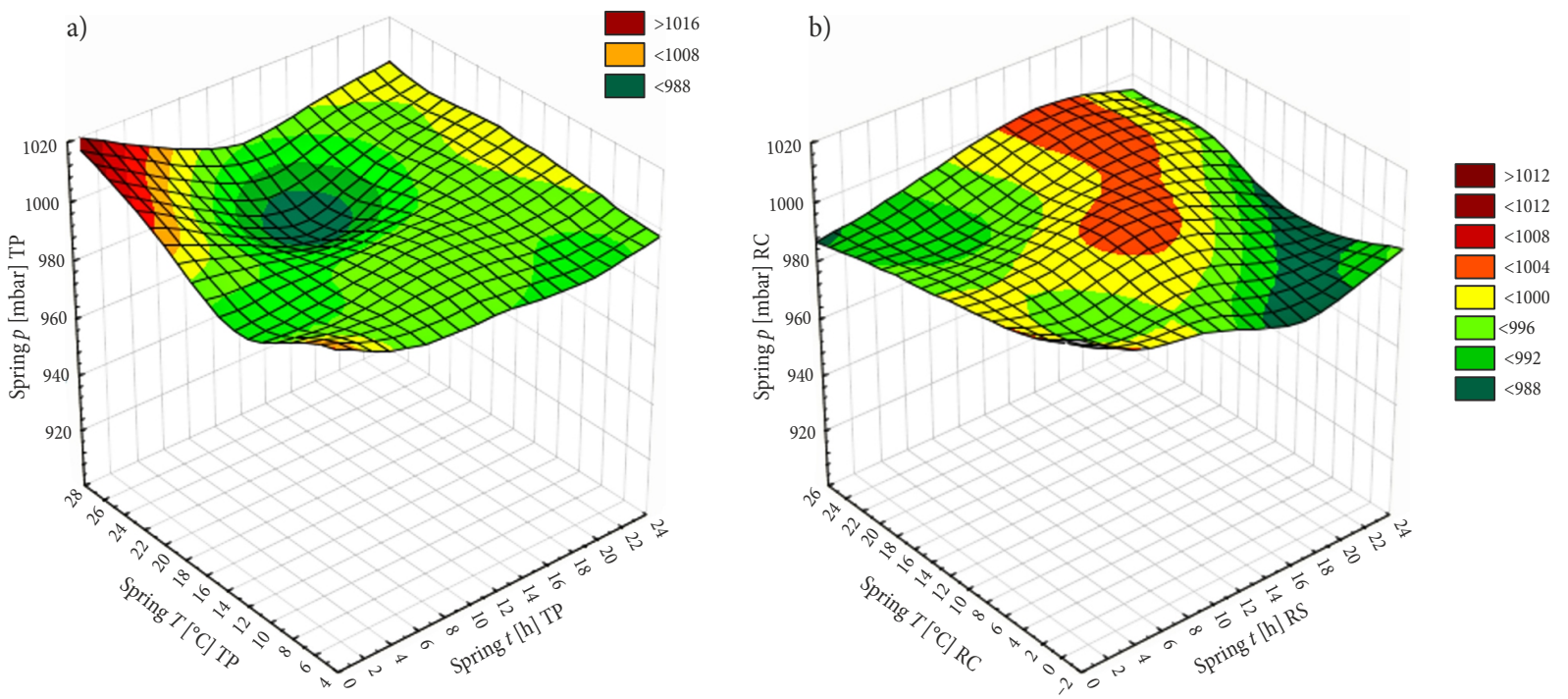

Figure 5. Distribution during spring: $\mathrm{a}$ - for TP; $\mathrm{b}$ - on RC
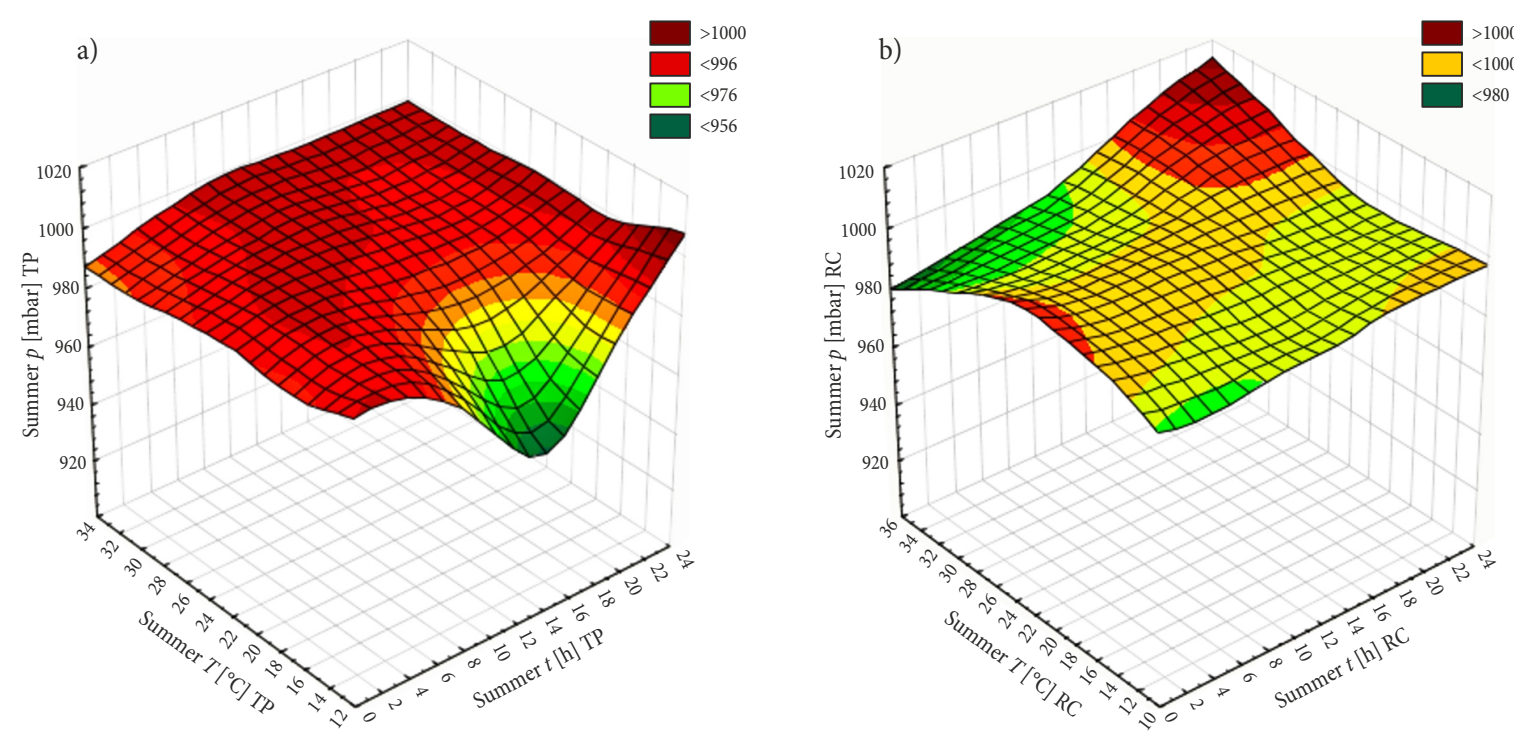

Figure 6. Distribution during summer: $\mathrm{a}$ - for TP; $\mathrm{b}$ - on RC
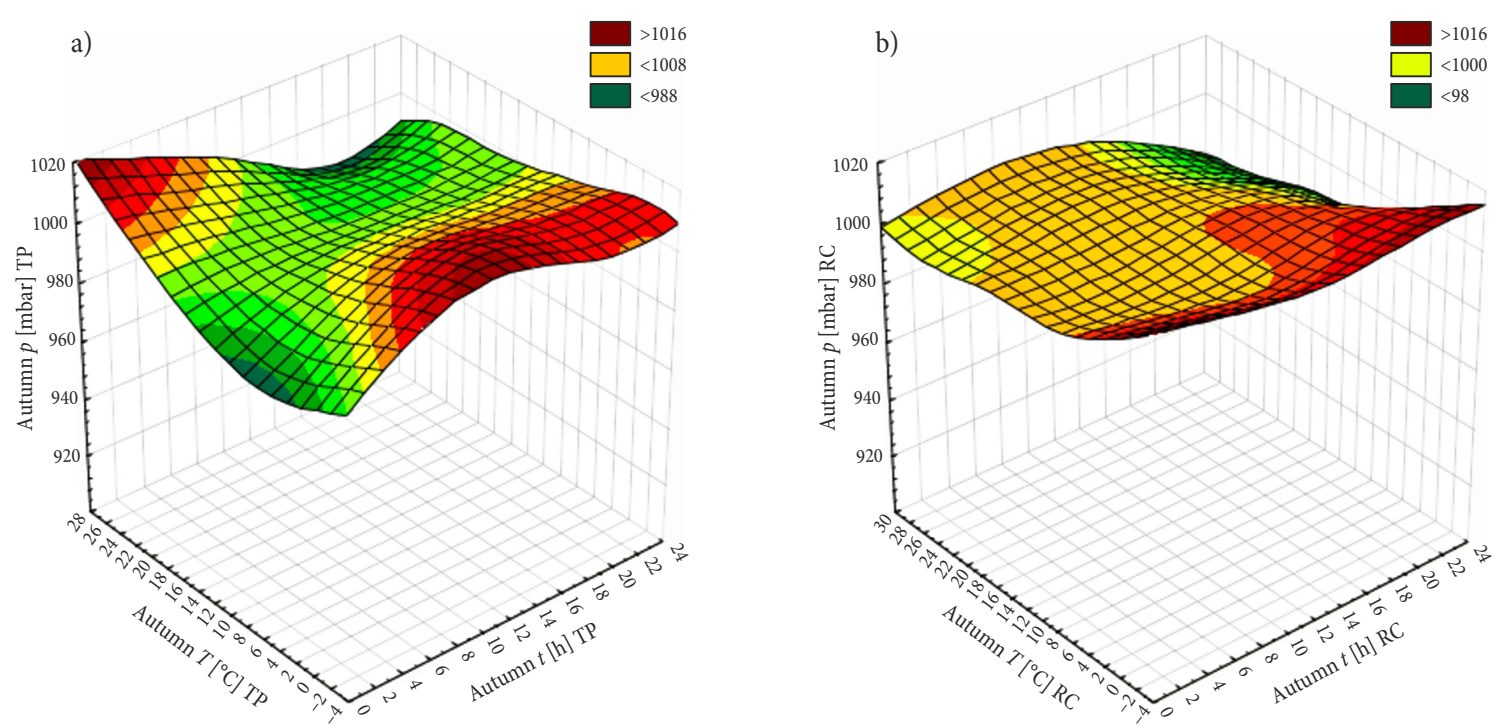

Figure 7. Distribution during autumn: $\mathrm{a}$ - for TP; $\mathrm{b}$ - on RC 
Table 1. Impact of seasonal factor ${ }^{7}$ on the values of atmospheric pressure in occurrence of railway accidents involving TP (above diagonal) and on RC (below diagonal)

\begin{tabular}{|l|c|c|c|c|}
\hline \multicolumn{1}{|c|}{ TP } & Winter & Spring & Summer & Autumn \\
\hline Winter & & 0.211646 & $\mathbf{0 . 0 4 2 2 3 5}$ & 0.460742 \\
\hline Spring & $\mathbf{0 . 0 0 0 3 3 6}$ & & 0.581276 & 0.639709 \\
\hline Summer & $\mathbf{0 . 0 0 0 0 2 1}$ & 0.898516 & & 0.311521 \\
\hline Autumn & 0.334794 & $\mathbf{0 . 0 0 1 8 0 6}$ & $\mathbf{0 . 0 0 0 1 8 5}$ & \\
\hline
\end{tabular}

As shown in Table 1, in railway accidents involving TP there is only one significant difference in variances of atmospheric pressure, between winter and summer $(p=0.042235)$. Generally, winter and summer have the highest meteorological extremes, while transition periods (autumn and spring) are without any significant differences. Conclusions about significant differences in variances of atmospheric pressures between railway accidents involving TP and at RC during winter $(p=$ $0.012741)$ and during summer $(p=0.004634)$ should be added to this analysis.

These results undoubtedly point to the existence of factors for railway accidents at RC as a function of atmospheric pressure and air temperature.

The analysis indicates that seasonal factors of railway accidents at RC have larger impact than the seasonal factors that lead to railway accidents involving TP. Since there are no significant differences for RC between autumn/winter period and spring/summer period, the data are compiled based on statistical compliance in order to obtain a larger statistical set. The analysis of comparative histograms (shown in Figure 3) emphasizes the frequencies of railway accidents on RC during autumn and winter for the values of atmospheric pressure higher than 1010 mbar. The frequencies are symbolically present for spring and negligible for summer period. Therefore, the analysis will focus only on accidents at RC. Accidents at $\mathrm{RC}$ during autumn and winter are selected for further analysis.

The function of the value of atmospheric pressure at which accidents at RC occurred is the invariant of the time of accident occurrence. This finding is surprising because of the daily variations in atmospheric pressure. However, the integration of data into a statistical set (autumn/winter) additionally reduces the impact of weather on occurrence of accidents at RC. This fact has been confirmed statistically. The ANOVA has not established either time or the time interval that would emphasize a significant difference with disjoint set of values of atmospheric pressure. The distribution of values of atmospheric pressure has been approximately equal for all times of railway accident occurrence.

Nevertheless, there are wide temperature intervals distinguished in accidents at RC as significant factors for the value of atmospheric pressure. In order to determine the critical pressure for the periods of autumn and winter, the method of sequential ANOVA has been applied. The sequential ANOVA is based on forming the disjoint sets of limit temperature and on the compliance of the sets' variances. The largest significant differences have been established in the temperature range from -5 to $0{ }^{\circ} \mathrm{C}$. The results are shown in Table 2 .

Based on sequential ANOVA, we conclude that the key value of pressure is about 1010 mbar at temperatures from -2 to $-1{ }^{\circ} \mathrm{C}$, as shown in Table 2 .

Histograms of distribution of temperatures and pressures for railway accidents at RC during autumn and winter (total of 266 cases) show significant asymmetry, and therefore cannot be described by normal distributions.

Distribution of temperature has parameters of mathematical expectation $\mu=7017$ and standard deviation $\sigma=8.780$. Due to the negative values of temperature, preparation of distribution for verification can be performed by translating along abscissa for $+15^{\circ} \mathrm{C}$. With a new parameter of mathematical expectation $\mu_{+15}=$ 22017, translated distribution is a significant Gamma distribution $(p=0.600>0.05)$, scale parameter $\theta=3.8837$ and shape parameter $k=5.6691$, which is confirmed by $\chi^{2}$ test $\left(\chi^{2}=3.6554\right.$ for $\left.d f=5\right)$. Distribution of atmospheric pressure with the parameters of mathematical expectation $\mu=1002634$ and standard deviation $\sigma=13.551$

Table 2. Results of sequential ANOVA in atmospheric pressure for railway accidents at RC in the temperature range from $-5{ }^{\circ} \mathrm{C}$ to $0{ }^{\circ} \mathrm{C}$, sequence $1{ }^{\circ} \mathrm{C}$

\begin{tabular}{|c|c|c|c|c|c|}
\hline $\mathrm{T}\left[{ }^{\circ} \mathrm{C}\right]$ & $N_{>T}{ }^{8}$ & air pressure [mbar] & $N_{<T}$ & Air pressure [mbar] & $p$ \\
\hline-5 & 251 & 1002.286 & 15 & 1008.268 & 0.086908 \\
\hline-4 & 244 & 1002.126 & 22 & 1008.453 & 0.041562 \\
\hline-3 & 238 & 1001.775 & 28 & 1009.936 & 0.002431 \\
\hline-2 & 229 & 1001.441 & 37 & $1010.016^{9}$ & 0.000312 \\
\hline-1 & 222 & 1001.241 & 44 & 1009.661 & 0.000141 \\
\hline 0 & 213 & 1001.272 & 53 & 1008.109 & 0.000927 \\
\hline
\end{tabular}

\footnotetext{
${ }_{7}$ Impact of seasonal factor - differences between the values of atmospheric pressure at the time of railway accidents during different seasons, obtained by the he ANOVA, indicate the impact of seasons on railway accident occurrence;
}

${ }^{8} N_{>T}$ - total number of railway accident that occurred at temperatures higher than $T$ (e.g. for $T>-3^{\circ} \mathrm{C}, N_{>T}=238$ railway accidents);

${ }^{9}$ Calculated key value of pressure, denoted by the authors as the critical value of air pressure. 
has a distinguished asymmetry and cannot be verified as normal. Significant verification of distributions of atmospheric pressure is achieved by Johnson $S_{U}$ distribution $(p>0.05)$ with parameters $\gamma=1.2761, \delta=1.8171$, $\lambda=16.2687, \xi=1017.0470$. Translated Gamma probability of density function for temperatures and Johnson $S_{U}$ probability of density function for atmospheric pressures with the aforementioned parameters are:

$$
\begin{aligned}
& f(T)=\frac{1}{\Gamma(k) \cdot \theta^{k}} \cdot(T+15)^{k-1} \cdot e^{-\frac{(T+15)}{\theta}} \\
& f(p)=\frac{\delta}{\lambda \cdot \sqrt{2 \cdot \pi}} \frac{1}{\sqrt{p^{2}+1}} \cdot e^{-\frac{1}{2} \cdot\left(\gamma+\delta \cdot \sinh ^{-1}\left(\frac{p-\xi}{\lambda}\right)\right)^{2}} .
\end{aligned}
$$

Histogram (Figure 8a) and empirical Cumulative Distribution Function (CDF) with histogram are shown in Figure 8b.

If we assume that, the temperature and pressure are not mutually conditioned and based on temperature interval of $5{ }^{\circ} \mathrm{C}$ and atmospheric pressure interval of 10 mbar, we can perform the distribution of frequencies $f_{i j(t)}$ according to the given intervals:

$$
f_{i j(t)}=n \cdot \frac{T_{i(t)}}{n} \cdot \frac{p_{j(t)}}{n}=\frac{T_{i(t)} \cdot p_{j(t)}}{n} .
$$

Table 3 shows the results of frequency distribution. The values represent the frequencies of two-dimensional random variables: railway accidents at railway crossing in autumn/winter as the function of temperature and atmospheric pressure. The values in Table 3 are used for probabilities calculated on the basis of the total number of accidents $(n=266)$ :

$$
\begin{aligned}
& P\left(T_{i(t)}\right)=\frac{T_{i(t)}}{n} \wedge P\left(p_{j(t)}\right)=\frac{p_{j(t)}}{n} \Leftrightarrow \\
& P\left(T_{i(t)} \cdot p_{j(t)}\right)=\frac{T_{i(t)}}{n} \cdot \frac{p_{j(t)}}{n}=\frac{f_{i j(t)}}{n^{2}} .
\end{aligned}
$$

a)

Variable: $(\mathrm{T}+15) \mathrm{RC}(\mathrm{W}+\mathrm{A})$, Distribution: Gamma Chi-Square test $=365547, d f=5$ (adjusted) $p=0.60001$

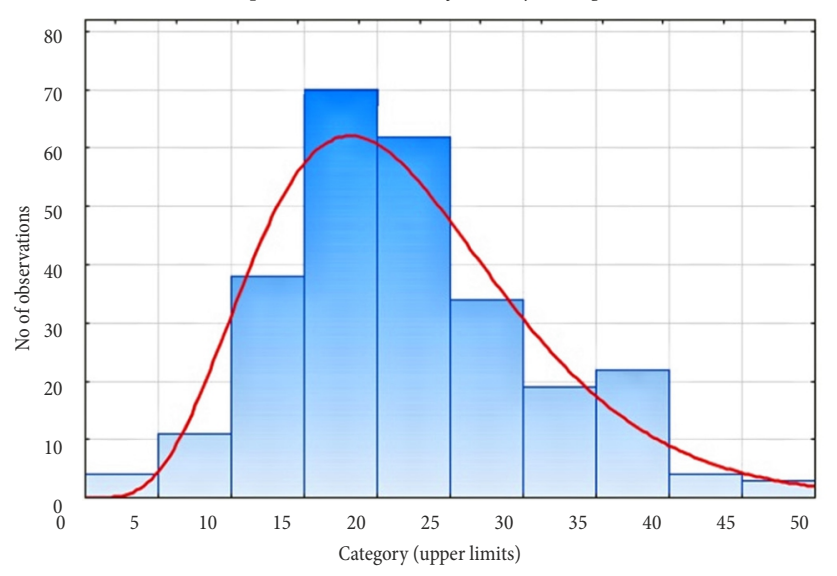

Conditional probabilities equal:

$$
\begin{aligned}
& P\left(\frac{T_{i(t)}}{p_{j(t)}}\right)=\frac{P\left(T_{i(t)} p_{j(t)}\right)}{P\left(p_{j(t)}\right)}=P\left(T_{i(t)}\right) ; \\
& P\left(\frac{p_{j(t)}}{T_{i(t)}}\right)=\frac{P\left(T_{i(t)} p_{j(t)}\right)}{P\left(T_{i(t)}\right)}=P\left(p_{j(t)}\right) .
\end{aligned}
$$

Theoretically, temperatures and atmospheric pressures are independent random variables.

Empirical frequencies are derived by counting the railway accidents that occurred at RC at specified intervals of temperature and atmospheric pressures (Figure 9). The function with the ordinate at $-20{ }^{\circ} \mathrm{C}$ has a logarithmic relationship between temperature and at-

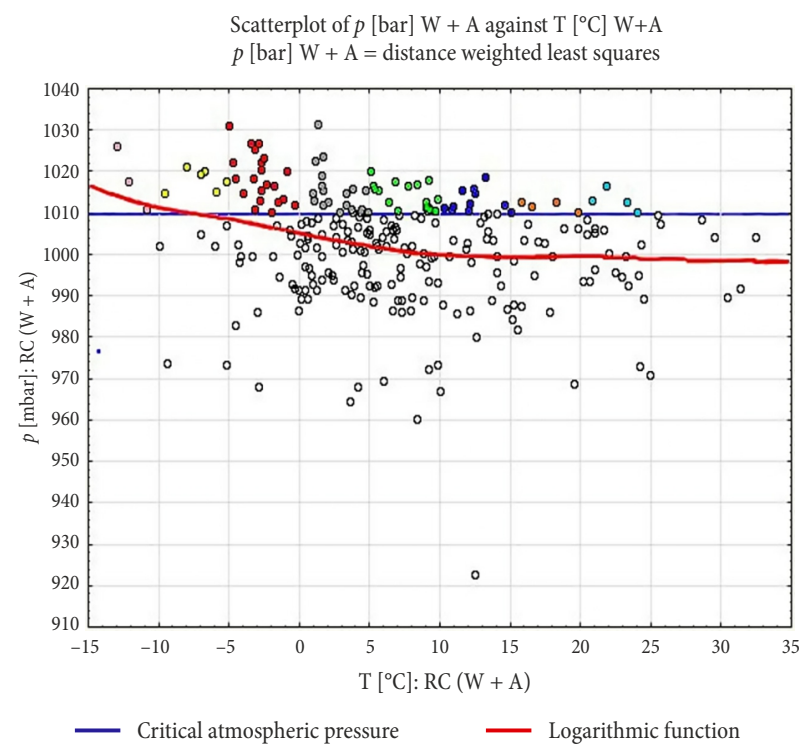

Figure 9. Empirical distribution of accidents at RC for the period autumn-winter

b)

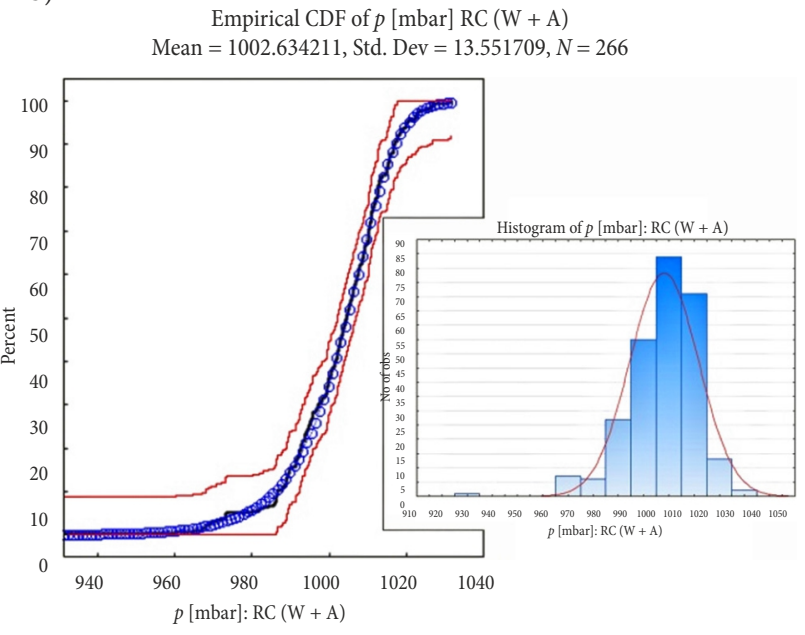

- Empirical CDF $\quad-$ Johnson _— 95\% lower confidence band _— 95\% upper confidence band

Figure 8. Histogram of frequencies of temperatures (a) and empirical CDF with histogram (b) 
mospheric pressure (it was necessary to translate the values of temperature along the ordinate for $+20^{\circ} \mathrm{C}$ in order to obtain logarithmic relationship). Logarithmic function $y=9.266 \cdot \ln (T+20)+1032.77$ has a correlation coefficient value of $\rho=0.234$. Graph of logarithmic functions and critical atmospheric pressure of 1010 mbar (obtained by sequential ANOVA) is highlighted in Table 3. Functional dependence of atmospheric pressure on temperature indicates a possible dependence of random variables in occurrence of accidents at RC.

Distributions of empirical frequencies of railway accidents at RC during autumn and winter as a function of temperature and pressure at specified intervals are shown in Table 4.

Comparative analysis of graphs of theoretical and empirical frequencies emphasize a clear difference between the maximum value of frequencies in the temperature range of $0<T_{4}<5{ }^{\circ} \mathrm{C}$ and in the atmospheric pressure range of $1000<p_{5}<1010 \mathrm{mbar}$, the theoretical frequency being $f_{45(t)}=22.11$ and the empirical one being $f_{45(e)}=25.00$ of railway accidents. The histograms of differences between theoretical and empirical frequencies $\left(t_{\text {heoretical }}-e_{\text {mpirical }}\right)$ are shown in Figure 10a (theoretical frequencies) and Figure 10b (empirical frequencies). The parameters of distribution are mathematical expectation $\mu=0$ and standard deviation $\sigma=1.7243$. Histogram of difference between theoretical and empirical frequencies and approximate graph of difference between theoretical and empirical frequencies as a function of temperature and atmospheric pressure are shown in Figure 11.

Distribution of difference between theoretical and empirical frequencies cannot be verified by a normal distribution ( $p=0.00057)$, which is why a $t$-test cannot be applied. The application of Signum test for verification of non-parametric hypothesis emphasizes a significant difference between the empirical and theoretical frequencies, $p=0.03364$ (for $n=80,10$ intervals of temperature and 8 intervals of atmospheric pressure interval, $Z=2.1242$ )

Theoretical values of frequencies of railway accidents $f_{i j(t)}$ at RC are derived according to the assumption of independence between the impacts of temperature and atmospheric pressure. However, the difference between theoretical and empirical frequencies is significant, while the functional dependence of temperature and atmospheric pressure is declared as logarithmic.

Table 3. Theoretical frequency of railway accidents at RC

\begin{tabular}{|c|c|c|c|c|c|c|c|c|c|c|c|}
\hline$p_{j(t)}[\mathrm{mbar}]$ & $\begin{array}{l}O \\
1 \\
v \\
-1 \\
v \\
v \\
i n \\
1\end{array}$ & $\begin{array}{l}i n \\
1 \\
v \\
\stackrel{1}{v} \\
v \\
0 \\
0\end{array}$ & $\begin{array}{l}0 \\
v \\
m \\
v^{m} \\
i n \\
1\end{array}$ & $\begin{array}{c}n \\
+ \\
v \\
v \\
+ \\
v \\
v \\
0\end{array}$ & $\begin{array}{l}\stackrel{0}{1} \\
+ \\
v \\
\text { in } \\
v \\
\text { in } \\
+\end{array}$ & $\begin{array}{l}n \\
+1 \\
v \\
0 \\
0 \\
v \\
0 \\
+ \\
+\end{array}$ & $\begin{array}{l}\text { i } \\
+ \\
v \\
N \\
v \\
v \\
\text { in } \\
+\end{array}$ & $\begin{array}{l}\stackrel{\sim}{T} \\
+ \\
v \\
\infty \\
\stackrel{\infty}{v} \\
\stackrel{2}{\stackrel{T}{+}}\end{array}$ & 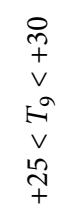 & 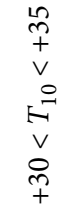 & $\sum T_{i(t)}$ \\
\hline $960<p_{1}<970$ & 0.09 & 0.36 & 1.14 & 2.11 & 1.86 & 0.99 & 0.57 & 0.66 & 0.12 & 0.09 & 8 \\
\hline $970<p_{2}<980$ & 0.07 & 0.27 & 0.86 & 1.58 & 1.40 & 0.74 & 0.43 & 0.50 & 0.09 & 0.07 & 6 \\
\hline $980<p_{3}<990$ & 0.30 & 1.22 & 3.86 & 7.11 & 6.29 & 3.35 & 1.93 & 2.23 & 0.41 & 0.30 & 27 \\
\hline $990<p_{4}<1000$ & 0.62 & 2.48 & 7.86 & 14.47 & 12.82 & 6.82 & 3.93 & 4.55 & 0.83 & 0.62 & 55 \\
\hline $1000<p_{5}<1010$ & 0.95 & 3.79 & 12.00 & 22.11 & 19.58 & 10.42 & 6.00 & 6.95 & 1.26 & 0.95 & 84 \\
\hline $1010<p_{6}<1020$ & 0.80 & 3.20 & 10.14 & 18.68 & 16.55 & 8.81 & 5.07 & 5.87 & 1.07 & 0.80 & 71 \\
\hline $1020<p_{7}<1030$ & 0.15 & 0.59 & 1.86 & 3.42 & 3.03 & 1.61 & 0.93 & 1.08 & 0.20 & 0.15 & 13 \\
\hline $1030<p_{8}<1040$ & 0.02 & 0.09 & 0.29 & 0.53 & 0.47 & 0.25 & 0.14 & 0.17 & 0.03 & 0.02 & 2 \\
\hline$\sum p_{j(t)}$ & 3 & 12 & 38 & 70 & 62 & 33 & 19 & 22 & 4 & 3 & 266 \\
\hline
\end{tabular}

Table 4. Empirical frequencies of accidents at RC

\begin{tabular}{|c|c|c|c|c|c|c|c|c|c|c|c|}
\hline$p_{j(e)}[\mathrm{mbar}]$ & $\begin{array}{l}0 \\
T \\
1 \\
v \\
\stackrel{1}{1} \\
v \\
i n \\
T\end{array}$ & $\begin{array}{l}i \\
1 \\
v \\
v \\
v \\
0 \\
0 \\
T\end{array}$ & $\begin{array}{l}0 \\
v \\
m \\
v \\
v \\
p\end{array}$ & $\begin{array}{l}n \\
+ \\
v \\
+4 \\
v \\
0 \\
0\end{array}$ & $\begin{array}{l}O \\
+ \\
v \\
\text { in } \\
v \\
v \\
\text { in } \\
+\end{array}$ & $\begin{array}{l}\frac{1}{7} \\
+ \\
v \\
v \\
1 \\
v \\
0 \\
+ \\
+\end{array}$ & $\begin{array}{l}\text { i } \\
+ \\
v \\
r \\
v \\
v \\
\text { in } \\
+\end{array}$ & 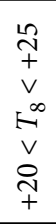 & $\begin{array}{l}\text { o } \\
+ \\
v \\
v \\
\text { r } \\
v \\
\stackrel{0}{N} \\
+ \\
+\end{array}$ & $\begin{array}{l}\stackrel{n}{m} \\
+ \\
v \\
\circ \\
\stackrel{9}{v} \\
v \\
\stackrel{m}{+} \\
+\end{array}$ & $\sum T_{i(e)}$ \\
\hline $960<p_{1}<970$ & 0 & 0 & 1 & 2 & 2 & 1 & 1 & 0 & 0 & 0 & 7 \\
\hline $970<p_{2}<980$ & 0 & 2 & 0 & 0 & 2 & 1 & 0 & 2 & 0 & 0 & 7 \\
\hline $980<p_{3}<990$ & 0 & 0 & 3 & 3 & 8 & 5 & 5 & 0 & 0 & 0 & 24 \\
\hline $990<p_{4}<1000$ & 0 & 0 & 8 & 20 & 14 & 5 & 3 & 8 & 0 & 2 & 60 \\
\hline $1000<p_{5}<1010$ & 0 & 4 & 6 & 25 & 19 & 11 & 6 & 8 & 4 & 1 & 84 \\
\hline $1010<p_{6}<1020$ & 2 & 5 & 12 & 17 & 17 & 10 & 4 & 4 & 0 & 0 & 71 \\
\hline $1020<p_{7}<1030$ & 1 & 1 & 7 & 2 & 0 & 0 & 0 & 0 & 0 & 0 & 11 \\
\hline $1030<p_{8}<1040$ & 0 & 0 & 1 & 1 & 0 & 0 & 0 & 0 & 0 & 0 & 2 \\
\hline$\sum p_{j(e)}$ & 3 & 12 & 38 & 70 & 62 & 33 & 19 & 22 & 4 & 3 & 266 \\
\hline
\end{tabular}



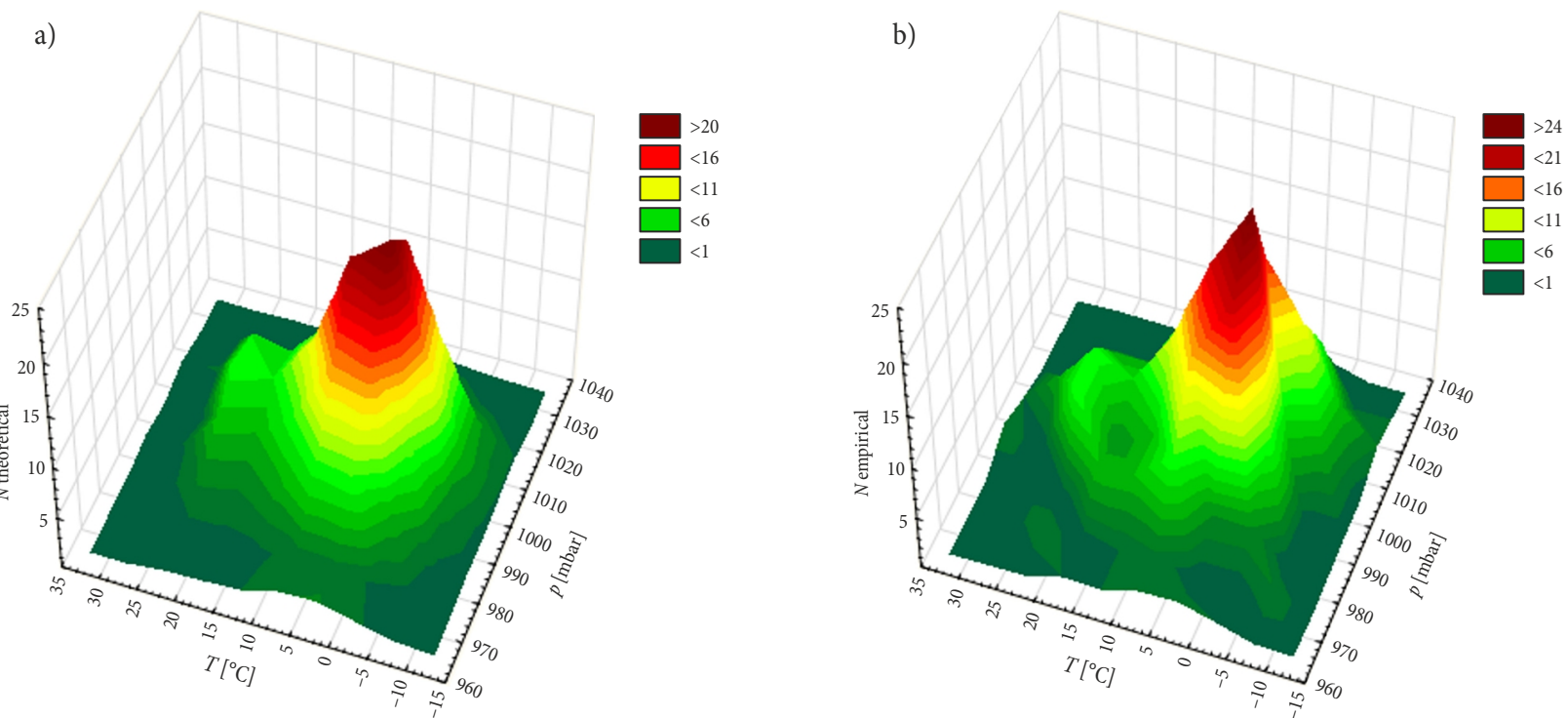

Figure 10. Distribution of: a - theoretical frequencies $f_{i j(t)}$; b - empirical frequencies $f_{i j(e)}$

a)

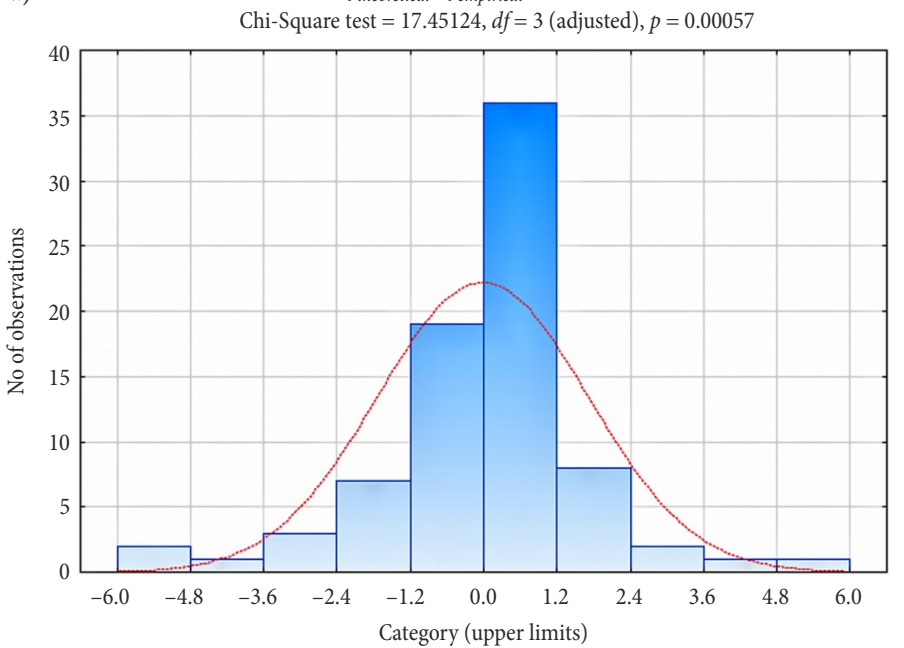

b)

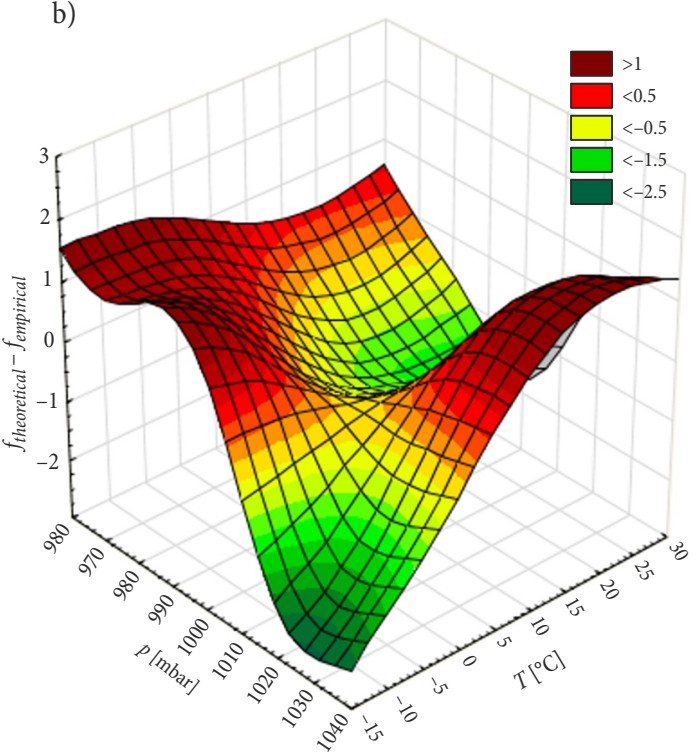

Figure 11. Histogram of difference between theoretical and empirical frequencies (a) and approximate graph of difference between theoretical and empirical frequencies (b)

After examining the approximate function of difference between empirical and theoretical frequencies (Figure $11 \mathrm{~b}$ ), we notice the largest differences appeared in the zone of low temperatures $T<0{ }^{\circ} \mathrm{C}$ and high atmospheric pressures $p>1010 \mathrm{mbar}$, i.e. for the value featured by the sequential ANOVA as a critical value (values are emphasized in previous tables).

\section{Application of Bayes' theorem (total probability theorem) in analysing the risk of accidents on RC}

Theoretical and empirical probabilities of accidents at RC during autumn and winter are derived as the quotient of theoretical $f_{i j(t)}$ and empirical $f_{i j(e)}$ frequencies divided by the total number of railway accidents, $n=266$.
A critical value of atmospheric pressure is determined by $p_{c}=1010$ mbar. A random railway accident in the zone of high atmospheric pressures $\left(p>p_{c}\right)$ is denoted as 'A', while ' $\mathrm{B}$ ' denotes a random railway accident in the zone of low atmospheric pressures $\left(p<p_{c}\right)$. Temperature intervals are disjoint sets, corresponding to the system of hypotheses in the concept of total probability for estimation of a priori probability. If $P\left(T_{i}\right)$ is a probability that the temperature in the area of railway crossing at the time of accident was in the temperature interval declared as $P\left(T_{i}\right)$, we get:

$$
\sum_{i=1}^{10} P\left(T_{i}\right)=P\left(T_{1}\right)+P\left(T_{2}\right)+\ldots+P\left(T_{10}\right)=1 .
$$

These probabilities are marginal totals for theoretical and empirical temperature values. 
Conditional probability:

$$
P\left(\frac{A}{T_{i}}\right)=\frac{P\left(A \cdot T_{i}\right)}{P\left(T_{i}\right)}
$$

is obtained from empirical distribution, by simple counting of the number of railway accidents in the zone of high atmospheric pressure in a predetermined temperature interval $T_{i}$. Tables 3 and 4 show that there were three railway accidents in the temperature range $-15 \leq T_{1}<-10{ }^{\circ} \mathrm{C}$, one having occurred in the interval of atmospheric pressure of $1020<p<1030 \mathrm{mbar}$ and two in the interval of $1010<p<1020$ mbar. The probability of occurrence of accidents at RC at a pressure value higher than 1010 mbar, provided that the temperature is in the range from $-15{ }^{\circ} \mathrm{C}$ to $-10{ }^{\circ} \mathrm{C}$ is 1 . Additionally, there was not a railway accident on railway crossing in the zone of temperatures over $25^{\circ} \mathrm{C}$ and pressures over 1010 mbar. Therefore, the relevant conditional probabilities are 0 . An analogous approach may also be applied in the zone of low atmospheric pressures. There are no railway accidents at temperatures lower than $-10{ }^{\circ} \mathrm{C}$ and pressures lower than 1010 mbar, while pressures at the time of accidents that occurred on RC at temperatures higher than $+25^{\circ} \mathrm{C}$ were lower than 1010 mbar. The biggest problem that may be solved by the concept of total probability is determining the probability of the product:

$$
\begin{aligned}
& P\left(A \cdot T_{i}\right)=P\left(T_{i}\right) \cdot P\left(\frac{A}{T_{i}}\right) ; \\
& P\left(B \cdot T_{i}\right)=P\left(T_{i}\right) \cdot P\left(\frac{B}{T_{i}}\right) .
\end{aligned}
$$

Table 5 shows values $P\left(A \cdot T_{i}\right)$ for air pressure higher than 1010 mbar, while Table 6 shows probabilities $P\left(B \cdot T_{i}\right)$ when the air pressure is lower than 1010 mbar. The obtained data are used for Table 7, i.e. for determining the risk of railway accident occurrence.

Table 5. Empirical conditional probabilities for distribution of accidents at RC at high atmospheric pressure for specific temperature ranges

\begin{tabular}{|c|c|c|c|c|c|}
\hline$T_{i}\left[{ }^{\circ} \mathrm{C}\right]$ & $N_{i}$ & $A_{i}>1010[\mathrm{mbar}]$ & $P\left(T_{i}\right)=\frac{N_{i}}{266}$ & $P\left(\frac{A}{T_{i}}\right)=\frac{A_{i}}{N_{i}}$ & $P\left(A \cdot T_{i}\right)$ \\
\hline$-15 \leq T_{1}<-10$ & 3 & 3 & $P\left(T_{1}\right)=0.0112$ & $P\left(A / T_{1}\right)=1.0000$ & $P\left(A T_{1}\right)=0.0112$ \\
\hline$-10 \leq T_{2}<-5$ & 12 & 6 & $P\left(T_{2}\right)=0.0451$ & $P\left(A / T_{2}\right)=0.5000$ & $P\left(A T_{2}\right)=0.0225$ \\
\hline$-5 \leq T_{3}<0$ & 38 & 20 & $P\left(T_{3}\right)=0.1428$ & $P\left(A / T_{3}\right)=0.5263$ & $P\left(A T_{3}\right)=0.0751$ \\
\hline $0 \leq T_{4}<+5$ & 70 & 20 & $P\left(T_{4}\right)=0.2631$ & $P\left(A / T_{4}\right)=0.2857$ & $P\left(A T_{4}\right)=0.0751$ \\
\hline$+5 \leq T_{5}<+10$ & 62 & 17 & $P\left(T_{5}\right)=0.2330$ & $P\left(A / T_{5}\right)=0.2741$ & $P\left(A T_{5}\right)=0.0639$ \\
\hline$+10 \leq T_{6}<+15$ & 33 & 10 & $P\left(T_{6}\right)=0.1240$ & $P\left(A / T_{6}\right)=0.3030$ & $P\left(A T_{6}\right)=0.0375$ \\
\hline$+15 \leq T_{7}<+20$ & 19 & 4 & $P\left(T_{7}\right)=0.0714$ & $P\left(A / T_{7}\right)=0.2105$ & $P\left(A T_{7}\right)=0.0150$ \\
\hline$+20 \leq T_{8}<+25$ & 22 & 4 & $P\left(T_{8}\right)=0.0827$ & $P\left(A / T_{8}\right)=0.1818$ & $P\left(A T_{8}\right)=0.0150$ \\
\hline$+25 \leq T_{9}<+30$ & 4 & 0 & $P\left(T_{9}\right)=0.0150$ & $P\left(A / T_{9}\right)=0.0000$ & $P\left(A T_{9}\right)=0.0000$ \\
\hline$+30 \leq T_{10}<+35$ & 3 & 0 & $P\left(T_{10}\right)=0.0112$ & $P\left(A / T_{10}\right)=0.0000$ & $P\left(A T_{10}\right)=0.0000$ \\
\hline$\sum T_{i}$ & 266 & 84 & 1.000 & 3.2814 & $0.3157=84 / 266$ \\
\hline
\end{tabular}

Table 6. Empirical conditional probabilities for distribution of accidents at RC at low atmospheric pressure $(p<1010$ mbar) for given temperature ranges

\begin{tabular}{|c|c|c|c|c|c|}
\hline$T_{i}\left[{ }^{\circ} \mathrm{C}\right]$ & $N_{i}$ & $B_{i}>1010[\mathrm{mbar}]$ & $P\left(T_{i}\right)=\frac{N_{i}}{266}$ & $P\left(\frac{B}{T_{i}}\right)=\frac{B_{i}}{N_{i}}$ & $P\left(B \cdot T_{i}\right)$ \\
\hline$-15 \leq T_{1}<-10$ & 3 & 0 & $P\left(T_{1}\right)=0.0112$ & $P\left(B / T_{1}\right)=0.0000$ & $P\left(B T_{1}\right)=0.0000$ \\
\hline$-10 \leq T_{2}<-5$ & 12 & 6 & $P\left(T_{2}\right)=0.0451$ & $P\left(B / T_{2}\right)=0.5000$ & $P\left(B T_{2}\right)=0.0226$ \\
\hline$-5 \leq T_{3}<0$ & 38 & 18 & $P\left(T_{3}\right)=0.1428$ & $P\left(B / T_{3}\right)=0.4736$ & $P\left(B T_{3}\right)=0.0677$ \\
\hline $0 \leq T_{4}<+5$ & 70 & 50 & $P\left(T_{4}\right)=0.2631$ & $P\left(B / T_{4}\right)=0.7142$ & $P\left(B T_{4}\right)=0.1879$ \\
\hline$+5 \leq T_{5}<+10$ & 62 & 45 & $P\left(T_{5}\right)=0.2330$ & $P\left(B / T_{5}\right)=0.7258$ & $P\left(B T_{5}\right)=0.1692$ \\
\hline$+10 \leq T_{6}<+15$ & 33 & 23 & $P\left(T_{6}\right)=0.1240$ & $P\left(B / T_{6}\right)=0.6969$ & $P\left(B T_{6}\right)=0.0865$ \\
\hline$+15 \leq T_{7}<+20$ & 19 & 15 & $P\left(T_{7}\right)=0.0714$ & $P\left(B / T_{7}\right)=0.7894$ & $P\left(B T_{7}\right)=0.0564$ \\
\hline$+20 \leq T_{8}<+25$ & 22 & 18 & $P\left(T_{8}\right)=0.0827$ & $P\left(B / T_{8}\right)=0.8181$ & $P\left(B T_{8}\right)=0.0677$ \\
\hline$+25 \leq T_{9}<+30$ & 4 & 4 & $P\left(T_{9}\right)=0.0150$ & $P\left(B / T_{9}\right)=1.0000$ & $P\left(B T_{9}\right)=0.0150$ \\
\hline$+30 \leq T_{10}<+35$ & 3 & 3 & $P\left(T_{10}\right)=0.0112$ & $P\left(B / T_{10}\right)=1.0000$ & $P\left(B T_{10}\right)=0.0113$ \\
\hline$\sum T_{i}$ & 266 & 182 & 1.000 & 6.718 & $0.6843=182 / 266$ \\
\hline
\end{tabular}


Table 7. Conditional probabilities for high $P\left(\frac{T_{i}}{A}\right)$ and low P $P\left(\frac{T_{i}}{B}\right)$ atmospheric pressures, differences of conditional probabilities, sign of differences and the ratio of conditional probabilities for the same temperature intervals

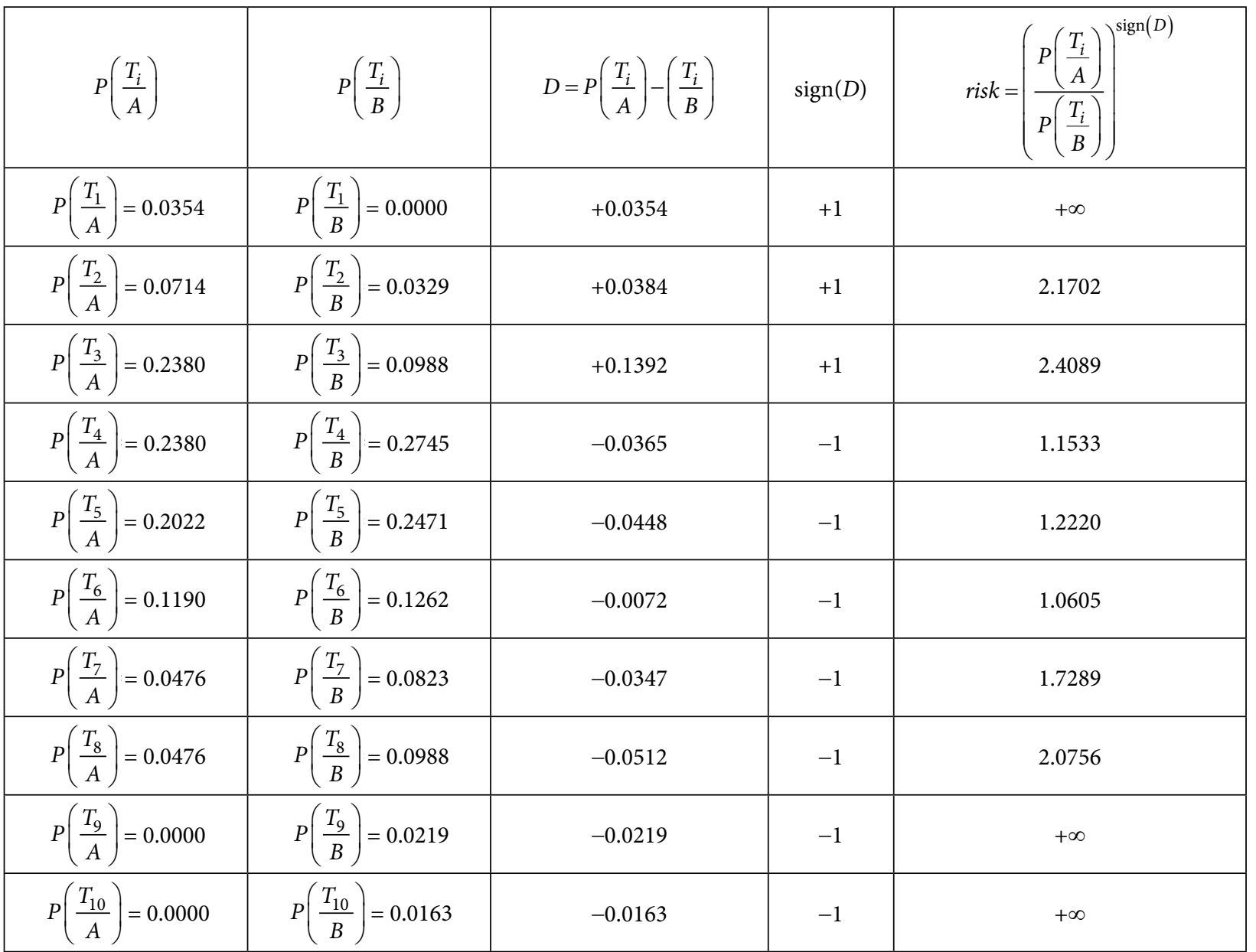

By application of Bayes' theorem:

$$
\begin{aligned}
& P\left(\frac{T_{i}}{A}\right)=\frac{P\left(\frac{A}{T_{i}}\right) \cdot P\left(T_{i}\right)}{P(A)} ; \\
& P\left(\frac{T_{i}}{B}\right)=\frac{P\left(\frac{B}{T_{i}}\right) \cdot P\left(T_{i}\right)}{P(B)} .
\end{aligned}
$$

Table 7 shows the calculated a posteriori conditional probabilities for high $P\left(\frac{T_{i}}{A}\right)$ and low $P\left(\frac{T_{i}}{B}\right)$ atmospheric pressures, differences of these conditional probabilities $D$, the sign of difference $\operatorname{sign}(D)$ and the quotient of conditional probabilities for the same temperature ranges. When the sign of difference is $\operatorname{sign}(D)=+1$, numerator is the conditional probability of high atmospheric pressure, while the denominator refers to low atmospheric pressures. If $\operatorname{sign}(D)=-1$, ratio of conditional probabilities has an inverse relationship. The quotient represents the risk of conditional probabilities of the same temperature intervals and complementary pressures.
Conditional probabilities of accidents occurrence on $\mathrm{RC}$ at the temperature range of $T \leq 0{ }^{\circ} \mathrm{C}$ and high atmospheric pressure are significantly higher than in complementary conditions and low atmospheric pressure.

As shown in Figure 12, the risk of railway accident in the temperature range of $-5 \leq T_{3}<0{ }^{\circ} \mathrm{C}$ at high atmospheric pressure $(p>1010$ mbar $)$ is $\approx 2.41$ times higher than the risk in the same temperature range at low atmospheric pressure $(p<1010$ mbar $)$. In the temperature range of $-10 \leq T_{2}<-5{ }^{\circ} \mathrm{C}$, high atmospheric pressure

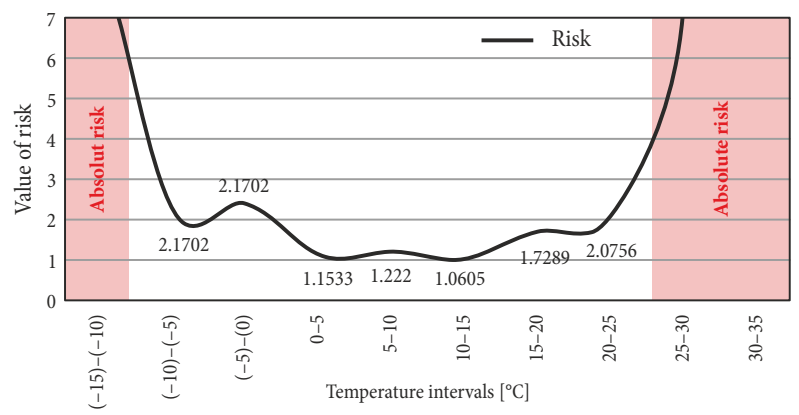

Figure 12. Risk of accident occurrence at RC at high temperatures and low air pressures for the sample of 266 observed cases 
gives $\approx 2.17$ times higher risk than the low atmospheric pressure in the same temperature range, which proves the absolute dominance of risk at $T<-10{ }^{\circ} \mathrm{C}$.

A higher risk of accident at $\mathrm{RC}$ is verified for all temperatures $T>0{ }^{\circ} \mathrm{C}$ at low atmospheric pressures. For temperatures in the range of $0 \leq T<+20^{\circ} \mathrm{C}$ the risk at low atmospheric pressure is between 1 and 2 , and for the temperature range of $+20 \leq T<+25^{\circ} \mathrm{C}$ the risk is $\approx 2.07$ higher at high atmospheric pressures. For temperature range of $T>+25^{\circ} \mathrm{C}$ the risk at low atmospheric pressure is absolute.

\section{Conclusions}

The research has started by collecting data about 3983 railway accidents on Serbian Railways in seven-year period. The authors have considered weather conditions for every railway accident, according to the data of the RHSS and depending on the location and time of accident. The weather conditions included air temperature, air pressure, dew point, pressure steam, relative humidity, pressure at sea level, changes in pressure for 3 hours, wind direction, wind speed, maximum wind speed, cloudiness, low clouds, the low clouds, the mean clouds, high clouds, visibility, precipitation, description of weather (past), etc. The research itself has been rather demanding, as most of the data are not electronic so that only archived records could have been used. A number of analyses performed during the research cannot be presented in this paper and they have not provided good results regarding the impact of weather conditions on railway accident occurrence both on the whole sample and on the sample of accidents caused by human factor.

However, air temperatures and air pressure have been distinguished as possible causes of railway accident occurrence caused by human factor on Serbian Railways for the observation time span. Therefore, they have been considered in this paper. Though the authors are aware of the possible impact on weather condition on technical systems (e.g. train braking system), the basic idea of this paper was to view railway accidents from a new point of view and technical issues may be considered and researched in the future.

The introduction of climatic factors in the analysis of railway accidents caused by human factors does not give significant results immediately and the impact becomes completely insignificant by observation of the entire sample. However, the logical assumption that extreme values of temperature and pressure have a significant impact on people's motor skills and, consequently, on occurrence of railway accidents, has proved true but only for a partial analysis, i.e. only in consideration of specific cases. The partial analysis included the sample of 266 railway accidents that occurred at RC in the observed period of autumn and winter. A high-risk value of railway accident is confirmed at low temperatures and high air pressures. Such specific climatic data indicate that in certain weather conditions it is necessary to introduce some measures in order to prevent the occurrence of railway accidents. However, introduction of manda- tory measures in such climatic conditions would require participation of scientists from other fields too, so that effects on people could have been defined more precisely, as well as the measures to be taken in order to prevent railway accidents.

The analysis of the observed sample of 266 accidents that occurred on RC shows that the risk of accident occurrence is significantly higher at low temperatures (from -10 to $0{ }^{\circ} \mathrm{C}$ ) and high air pressures $(p>1010 \mathrm{mbar})$, the risk being 2.17, that is 2.41 times higher than in standard (average) weather conditions. Additionally, in the case of high temperatures (above $20^{\circ} \mathrm{C}$ ) and low air pressures $(p<1010$ mbar) the risk rises to 2.07 in comparison to average weather conditions. The absolute risk of railway accident occurrence appears at temperatures below $-10{ }^{\circ} \mathrm{C}$ and air pressures higher than $1010 \mathrm{mbar}$, as well as at high temperatures $\left(T>25^{\circ} \mathrm{C}\right)$ and air pressures lower than 1010 mbar.

Although only a partial effect of temperature and air pressure on the occurrence of railway accidents caused by the human factor has been proved, authors would like to think that this might be a good start and basis for further research of this issue. In addition to the approach used in this research, there is a number of possibilities for further research, perhaps by using some other methodologies that might give better results and higher interdependence between climate and occurrence of railway accidents caused by a human factor.

\section{References}

Baysari, M. T.; McIntosh, A. S.; Wilson J. R. 2008. Understanding the human factors contribution to railway accidents and incidents in Australia, Accident Analysis \& Prevention 40(5): 1750-1757. https://doi.org/10.1016/j.aap.2008.06.013

Cedergren, A.; Petersen, K. 2011. Prerequisites for learning from accident investigations: a cross-country comparison of national accident investigation boards, Safety Science 49(8-9): 1238-1245.

https://doi.org/10.1016/j.ssci.2011.04.005

Clark, H. E.; Perrone, J. A.; Isler, R. B. 2013. An illusory sizespeed bias and railway crossing collisions, Accident Analysis \& Prevention 55: 226- 231.

https://doi.org/10.1016/j.aap.2013.02.037

Daanen, H. A. M.; Van de Vliert, E.; Huang, X. 2003. Driving performance in cold, warm, and thermoneutral environments, Applied Ergonomics 34(6): 597-602. https://doi.org/10.1016/S0003-6870(03)00055-3

Deschenes, O. 2014. Temperature, human health, and adaptation: a review of the empirical literature, Energy Economics 46: 606-619. https://doi.org/10.1016/j.eneco.2013.10.013

Edkins, G. D.; Pollock, C. M. 1997. The influence of sustained attention on Railway accidents, Accident Analysis \& Prevention 29(4): 533-539. http://dx.doi.org/10.1016/S0001-4575(97)00033-X

Evans, A. W. 2011. Fatal train accidents on Europe's railways: 1980-2009, Accident Analysis \& Prevention 43(1): 391-401. https://doi.org/10.1016/j.aap.2010.09.009

Evans, A. W. 2010. Rail safety and rail privatisation in Japan, Accident Analysis \& Prevention 42(4): 1296-1301. https://doi.org/10.1016/j.aap.2010.02.007 
Evans, A. W. 2007. Rail safety and rail privatisation in Britain, Accident Analysis \& Prevention 39(3): 510-523. https://doi.org/10.1016/j.aap.2006.09.007

Evans, A. W. 2003. Estimating transport fatality risk from past accident data, Accident Analysis \& Prevention 35(4): 459-472. https://doi.org/10.1016/S0001-4575(02)00024-6

Evans, A. W.; Verlander, N. Q. 1996. Estimating the consequences of accidents: the case of automatic train protection in Britain, Accident Analysis \& Prevention 28(2): 181-191. https://doi.org/10.1016/0001-4575(95)00057-7

Hsiang, S. M.; Burke, M.; Miguel, E. 2013. Quantifying the influence of climate on human conflict, Science 341(6151): 1189-1213. https://doi.org/10.1126/science.1235367

Imbeault, M.-A.; Mantha, O. L.; Haman, F. 2013. Shivering modulation in humans: effects of rapid changes in environmental temperature, Journal of Thermal Biology 38(8): 582-587. https://doi.org/10.1016/j.jtherbio.2013.10.002

Liu, W.; Deng, Q.; Ma, W.; Huangfu, H.; Zhao, J. 2013. Feedback from human adaptive behavior to neutral temperature in naturally ventilated buildings: physical and psychological paths, Building and Environment 67: 240-249. http://doi.org/10.1016/j.buildenv.2013.05.024

Lobb, B.; Harre, N.; Suddendorf, T. 2001. An evaluation of a suburban railway pedestrian crossing safety programme, Accident Analysis \& Prevention 33(2): 157-165. https://doi.org/10.1016/S0001-4575(00)00026-9

Lobb, B.; Harré, N.; Terry, N. 2003. An evaluation of four types of railway pedestrian crossing safety intervention, Accident Analysis \& Prevention 35(4): 487-494. https://doi.org/10.1016/S0001-4575(02)00026-X

Mirabadi, A.; Sharifian, S. 2010. Application of association rules in Iranian Railways (RAI) accident data analysis, Safety Science 48(10): 1427-1435. https://doi.org/10.1016/j.ssci.2010.06.006

Naweed, A. 2013. Psychological factors for driver distraction and inattention in the Australian and New Zealand rail industry, Accident Analysis \& Prevention 60: 193-204. https://doi.org/10.1016/j.aap.2013.08.022

Oh, J.; Washington, S. P.; Nam, D. 2006. Accident prediction model for railway-highway interfaces, Accident Analysis \& Prevention 38(2): 346-356. https://doi.org/10.1016/j.aap.2005.10.004

Ouyang, M.; Hong, L.; Yu, M.-H.; Fei, Q. 2010. STAMP-based analysis on the railway accident and accident spreading: taking the China-Jiaoji railway accident for example, Safety Science 48(5): 544-555. https://doi.org/10.1016/j.ssci.2010.01.002

Rådbo, H.; Svedung, I.; Andersson, R. 2008. Suicide prevention in railway systems: application of a barrier approach, Safety Science 46(5): 729-737. https://doi.org/10.1016/j.ssci.2006.12.003

Schlader, Z. J.; Simmons, S. E.; Stannard, S. R.; Mündel, T. 2011. The independent roles of temperature and thermal perception in the control of human thermoregulatory behavior, Physiology \& Behavior 103(2): 217-224. https://doi.org/10.1016/j.physbeh.2011.02.002

Schlader, Z. J.; Stannard, S. R.; Mündel, T. 2010. Human thermoregulatory behavior during rest and exercise: a prospective review, Physiology \& Behavior 99(3): 269-275. https://doi.org/10.1016/j.physbeh.2009.12.003

Silla, A.; Kallberg, V.-P. 2012. The development of railway safety in Finland, Accident Analysis \& Prevention 45: 737- 744. https://doi.org/10.1016/j.aap.2011.09.043
Silla, A.; Luoma, J. 2012. Main characteristics of train-pedestrian fatalities on Finnish railroads, Accident Analysis \& Prevention 45: 61- 66. https://doi.org/10.1016/j.aap.2011.11.008

Størseth, F.; Tinmannsvik, R. K. 2012. The critical re-action: learning from accidents, Safety Science 50(10): 1977-1982. https://doi.org/10.1016/j.ssci.2011.11.003

Tey, L.-S.; Ferreira, L.; Wallace, A. 2011. Measuring driver responses at railway level crossings, Accident Analysis \& Prevention 43(6): 2134- 2141. https://doi.org/10.1016/j.aap.2011.06.003

Underwood, P.; Waterson, P. 2014. Systems thinking, the Swiss cheese model and accident analysis: a comparative systemic analysis of the Grayrigg train derailment using the ATSB, AcciMap and STAMP models, Accident Analysis \& Prevention 68: 75-94. https://doi.org/10.1016/j.aap.2013.07.027 